The INL is a

U.S. Department of Energy

National Laboratory

operated by

Battelle Energy Alliance

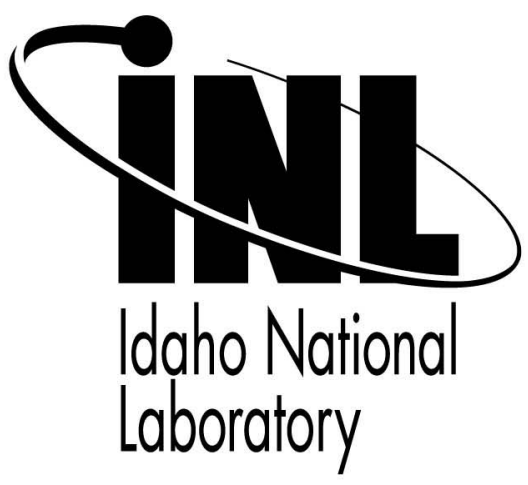

INL/CON-08-14226

PREPRINT

\section{Pebble Bed Reactor Dust Production Model}

Joshua J. Cogliati
Abderrafi M. Ougouag

September 2008

This is a preprint of a paper intended for publication in a journal or proceedings. Since changes may be made before publication, this preprint should not be cited or reproduced without permission of the author. This document was prepared as an account of work sponsored by an agency of the United States Government. Neither the United States Government nor any agency thereof, or any of their employees, makes any warranty, expressed or implied, or assumes any legal liability or responsibility for any third party's use, or the results of such use, of any information, apparatus, product or process disclosed in this report, or represents that its use by such third party would not infringe privately owned rights. The views expressed in this paper are not necessarily those of the United States Government or the sponsoring agency. 


\section{Proceedings of the $4^{\text {th }}$ International Topical Meeting on High Temperature Reactor Technology HTR2008 \\ September 28-October 1, 2008, Washington, DC USA}

\section{HTR2008-58289}

\section{PEBBLE BED REACTOR DUST PRODUCTION MODEL}

\author{
Joshua J. Cogliati \\ Idaho National Laboratory \\ Idaho Falls, Idaho, USA \\ Joshua.Cogliati@inl.gov
}

\author{
Abderrafi M. Ougouag \\ Idaho National Laboratory \\ Idaho Falls, Idaho, USA \\ Abderrafi.Ougouag@inl.gov
}

\begin{abstract}
The operation of pebble bed reactors, including fuel circulation, can generate graphite dust, which in turn could be a concern for internal components; and to the near field in the remote event of a break in the coolant circuits. The design of the reactor system must, therefore, take the dust into account and the operation must include contingencies for dust removal and for mitigation of potential releases. Such planning requires a proper assessment of the dust inventory. This paper presents a predictive model of dust generation in an operating pebble bed with recirculating fuel. In this preliminary work the production model is based on the use of the assumption of proportionality between the dust production and the normal force and distance traveled. The model developed in this work uses the slip distances and the inter-pebble forces computed by the authors' PEBBLES. The code, based on the discrete element method, simulates the relevant static and kinetic friction interactions between the pebbles as well as the recirculation of the pebbles through the reactor vessel. The interaction between pebbles and walls of the reactor vat is treated using the same approach. The amount of dust produced is proportional to the wear coefficient for adhesive wear (taken from literature) and to the slip volume, the product of the contact area and the slip distance. The paper will compare the predicted volume with the measured production rates. The simulation tallies the dust production based on the location of creation. Two peak production zones from intra pebble forces are predicted within the bed. The first zone is located near the pebble inlet chute due to the speed of the dropping pebbles. The second peak zone occurs lower in the reactor with increased pebble contact force due to the weight of supported pebbles. This paper presents the first use of a Discrete Element Method simulation of pebble bed dust production.
\end{abstract}

\section{INTRODUCTION}

The gas-cooled graphite-moderated pebble bed reactor is a leading concept for the Next Generation Nuclear Plant, a Very High Temperature Reactor, under consideration in the US at the Idaho National Laboratory. Other pebble bed reactors are being designed and planned for construction by Pebble Bed Modular Reactor Limited in the Republic of South Africa and at the Tsinghua University in China.

The pebble bed reactor uses spherical graphite pebbles as fuel elements. Each pebble contains thousands of TRISO fuel particles. These pebbles are dropped into the top of the reactor, and then they travel down the reactor to the outlet chute below. At the bottom the pebbles are removed and the burnup determines whether the pebble recirculates or is removed from use. The motion of these pebbles as they travel through the reactor produces graphite dust which is a concern.

This graphite dust will then travel through the cooling system. The Helium used as coolant only becomes trivially radioactive, so the graphite and impurities in the graphite are the primary source of ionizing radiation away from the fuel elements. The dust can decrease the efficiency of the heat exchanger and for direct cycle high temperature gas reactors the graphite particles colliding with the turbine blades will decrease their operating lifetime. In the Arbeitsgemeinschaft Versuchs-Reaktor (AVR) pebble bed reactor $3 \mathrm{~kg}$ of graphite dust was produced per operating year. The characterization of this dust production will answer key questions about the feasibility of Pebble Bed Reactors.

Using a discrete element approach, this paper calculates the dust production of the motion of the pebbles. The contact forces between each pebble in the reactor are calculated as pebbles are recirculated in the reactor. The calculated dust production values while low, are plausible considering limitations of the simulation and existing experimental data. The methods of improving this prediction are examined in the paper. 


\section{METHODOLOGY}

The moving pebbles wear against each other and the other surfaces that they come into contact with including the fuel handing system and the graphite reflectors in the core. The exact dust production depends on the microscopic surface conditions that exist in the graphite. Relevant factors include the temperature, the atmosphere, the normal force and the past history of wear. The Modern Tribology Handbook provides this first order approximation for calculating the dust production volume:

$$
V=K_{a d} \frac{N}{H} L
$$

In this equation $V$ is the wear volume, $K_{a d}$ is the wear coefficient for adhesive wear, $L$ is the length slide and $N / H$ is the real contact area (with $N$ the normal force and $H$ the hardness). This equation is only approximate, since the volume is not perfectly proportional [1]. The PEBBLES simulation calculates

$$
\sum\left|\mathbf{v}_{\| i j} \| \mathbf{F}_{\perp i j}\right|
$$

where $\mathbf{v}_{\| i j}$ is the component of the velocity between two pebbles perpendicular to the line joining them since $\mathbf{v}_{\| i j} d t$ is the length slide and $\mathbf{F}_{\perp i j}$ is the normal force between pebbles $i$ and $j$. This is summed over all the pebbles in the simulation and all the time and can be multiplied by the wear coefficient over the hardness and a time delta to produce the quantity of dust produced. The next section describes the method of calculating the velocity and force.

\section{IMPLEMENTATION}

The PEBBLES code simulates the motion of pebbles in a pebble bed reactor using the Discrete Element Method. Each pebble in the reactor is simulated separately. The pebbles have a force of gravity, a Hooke's law force and friction forces to allow the subsequent motion to be calculated.

The classical mechanics time derivatives[2] are integrated to produce the subsequent locations, velocities and angular velocities. The following time derivatives are used:

$$
\begin{gathered}
\frac{d \mathbf{v}_{i}}{d t}=\frac{m_{i} \mathbf{g}+\sum_{i \neq j} \mathbf{F}_{i j}+\mathbf{F}_{c i}}{m_{i}} \\
\frac{d \mathbf{p}_{i}}{d t}=\mathbf{v}_{i} \\
\frac{d \boldsymbol{\omega}_{i}}{d t}=\frac{\sum_{i \neq j} \mathbf{F}_{\| i j} \times r_{i} \hat{\mathbf{n}}_{i j}}{I_{i}}
\end{gathered}
$$

With these equations $\mathbf{F}_{i j}$ is the force from pebble $j$ on pebble $i$, $\mathbf{F}_{c i}$ is the force of the container on pebble $i, \mathbf{g}$ is the gravitational acceleration constant, $m_{i}$ is the mass of pebble $i, \mathbf{v}_{i}$ is the velocity of pebble $i, \mathbf{p}_{i}$ is the position vector for pebble $i, \boldsymbol{\omega}_{i}$ is the angular velocity of pebble $i, \mathbf{F}_{\| i j}$ is the tangential force between pebbles $i$ and $j, r_{i}$ is the radius of pebble $i, I_{i}$ is the moment of inertia for pebble $i$ and $\hat{\mathbf{n}}_{i j}$ is the unit vector pointing from the position of pebble $i$ to that of pebble $j$.
The dynamic friction forces are based on the model in Wait[3]. Wait's and PEBBLES model calculates the dynamic friction using a combination of the relative velocities and pressure between the pebbles, as shown in Eqs. (6) and (7):

$$
\begin{gathered}
\mathbf{F}_{\perp i j}=h l_{i j} \hat{\mathbf{n}}_{i j}-C_{\perp} \mathbf{v}_{\perp i j}, l_{i j}>0 \\
\mathbf{F}_{d \| i j}=-\min \left(\mu\left|\mathbf{F}_{\perp i j}\right|, C_{\|}\left|\mathbf{v}_{\| i j}\right|\right) \hat{\mathbf{v}}_{\| i j}, l_{i j}>0
\end{gathered}
$$

where $C_{\|}$is the tangential dashpot constant, $C_{\perp}$ is the normal dashpot constant, $\mathbf{F}_{\perp i j}$ is the normal force between pebbles $i$ and $j, \mathbf{F}_{d \| i j}$ is the tangential dynamic friction force between pebbles $i$ and $j, h$ is the normal Hooke's law constant, $l_{i j}$ is the overlap between pebbles $i$ and $j, \mathbf{v}_{\| i j}$ is the component of the velocity between two pebbles perpendicular to the line joining their centers, $\mathbf{v}_{\perp i j}$ is the component of the velocity between two pebbles parallel to the line joining their centers, $\mathbf{v}_{i j}$ is the relative velocity between pebbles $i$ and $j$ and $\mu$ is the kinetic friction coefficient. Eqs. (8-11) relate supplemental variables to the primary variables:

$$
\begin{gathered}
\mathbf{v}_{i j}=\left(\mathbf{v}_{i}+\boldsymbol{\omega}_{i} \times r_{i} \hat{\mathbf{n}}_{i j}\right)-\left(\mathbf{v}_{j}+\omega_{j} \times r_{j} \hat{\mathbf{n}}_{j i}\right) \\
\mathbf{F}_{i j}=\mathbf{F}_{\perp i j}+\mathbf{F}_{\| i j} \\
\mathbf{v}_{\perp i j}=\left(\mathbf{v}_{i j} \cdot \hat{\mathbf{n}}_{i j}\right) \hat{\mathbf{n}}_{i j} \\
\mathbf{v}_{\| i j}=\mathbf{v}_{i j}-\mathbf{v}_{\perp i j}
\end{gathered}
$$

The static friction model is a simplified version of $\mathrm{Vu}-\mathrm{Quoc}$ and Zhang[4]. This model allows sliding between pebbles, but assumes that as the pebbles slide they build up static friction force counter to the direction of slide. This method replicates real static friction effects including non-zero angles of repose and bridging in small outlet chutes.

At each timestep, the slip between the pebbles is updated. Updating relates the previous static friction slip to the newly calculated value slip and updates the direction:

$$
\begin{gathered}
\mathbf{s}_{p}=\mathbf{s}_{o}-\left(\mathbf{s}_{o} \cdot \hat{\mathbf{n}}\right) \hat{\mathbf{n}} \\
\mathbf{s}=\left|\mathbf{S}_{o}\right| \frac{\mathbf{s}_{p}}{\mathbf{S}_{p} \mid} \\
\mathbf{s}_{n}=\mathbf{S}+\mathbf{v}_{\| i j} \Delta t
\end{gathered}
$$

where $s_{o}$ is the previous slip, $\Delta t$ is the timestep and $s_{n}$ is the new value for the slip.

The new value for the slip is then used to calculate the force of static friction with the equation:

$\mathbf{F}_{s \| i j}=-\min \left(\mu_{s}\left|\mathbf{F}_{\perp i j}\right|, h_{s} \mid \mathbf{s}_{i j}\left[1-\frac{\left|\mathbf{v}_{\| i j}\right|}{v_{\max }}\right]\right) \hat{\mathbf{s}}_{i j},\left|\mathbf{v}_{\| i j}\right|<v_{\max }$

where $\mathbf{F}_{s \| i j}$ is the static friction force between pebbles $i$ and $j, h_{s}$ is the coefficient for force from slip, $\mathbf{s}_{i j}$ is the slip distance perpendicular to the normal force between pebbles $i$ and $j, v_{\max }$ is the maximum velocity under which static friction is allowed to operate and $\mu_{s}$ is the static friction coefficient. The static and dynamic friction are combined to get the total tangential force between pebbles with the supplemental equation: 


$$
\mathbf{F}_{\| i j}=\mathbf{F}_{s \| i j}+\mathbf{F}_{d \| i j}
$$

Recirculation of the pebbles is simulated via removing a pebble from the bottom of the reactor, and dropping in a new pebble at the top of the reactor. Similar equations are used for calculation of the wall interactions with modified equations for determination of relative velocity and the normal direction.

\begin{tabular}{|c|c|}
\hline Constant & Value \\
\hline Gravitational Acceleration $\mathbf{g}$ & $9.8 \mathrm{~m} / \mathrm{s}^{2}$ \\
\hline Mass of pebble $m$ & $\pi * 7.2 \mathrm{e}-5 \mathrm{~kg}$ \\
\hline Pebble moment of inertia $I$ & $\pi * 2.592 \mathrm{e}-8 \mathrm{~kg} \mathrm{~m}^{2}$ \\
\hline Radius of pebble $r$ & $0.03 \mathrm{~m}$ \\
\hline Hooke's law constant $h$ & $1000.0 \mathrm{~N} / \mathrm{m}$ \\
\hline Dashpot constants $C_{\|}$and $C_{\perp}$ & 0.1 \\
\hline Kinetic friction coefficient $\mu$ & 0.4 \\
\hline Static friction coefficient $\mu_{s}$ & 0.65 \\
\hline Static friction hooke $h_{s}$ & 1000.0 \\
\hline Maximum static friction velocity $v_{\max }$ & $0.1 \mathrm{~m} / \mathrm{s}$ \\
\hline
\end{tabular}

\section{Table 1 Constants used in Simulation}

The simulation uses smaller values for the mass and the Hooke's law constant. This substantially speeds up the simulation since fully realistic values require very small timesteps to have the simulation remain stable[5]. In order to compensate, the forces calculated for the dust production are multiplied by the ratio between a true pebble mass and the simulated pebble mass. This allows the correct normal force for dust production to be obtained.

\section{RESULTS}

In order to compare the of the dust production simulation to measured dust production in a reactor, a model of the $46 \mathrm{MW}$ thermal high temperature AVR was produced. AVR was built in the 1960s in Germany and operated for 21 years. The core of the reactor is a single 3 meter in diameter vat with an outlet cone connecting to a 0.5 meter in diameter discharge chute. The average inlet temperature of the helium coolant was $250^{\circ} \mathrm{C}$ and the average outlet temperature was $950^{\circ} \mathrm{C}$. A year of operation produced $3 \mathrm{~kg}$ of graphite dust, and each day 300 to 500 graphite spheres were circulated[6]. This reactor was modeled with the PEBBLES code. Due to the size of the reactor and the time required to simulate fully recalculating the reactor bed, the bed was not recirculated before the simulation of the dust production.

The dust production was tallied as a function of height in the reactor. Four hundred forty pebbles were recirculated and the resulting dust production was tallied. Based on simulation data two peak areas of dust production are predicted. The first zone is where the pebbles from the inlet chute impact the existing pebbles in the core. The incoming pebble gains velocity when falling from the inlet chute, and then impacts the existing pile of pebbles producing dust and vibration. The impulse momentarily produces dust as the pulse travels down the reactor. This is seen in the two meter zone in Figure 1. The second zone of high dust production is in the bottom of the reactor where the pressures are highest and the cone forces the pebbles to move laterally. With the dust produced by pebbles moving against the wall, there is no initial peak, but the dust production increases gradually for the first meter after the top of the pile, and then levels off as shown in Figure 2. The majority of pebble-wall dust is produced in the outlet cone because of the downward pressure from above pebbles. Over $97 \%$ of the dust in the core is produced by the more common pebble-pebble interactions compared to the pebble-wall interactions.

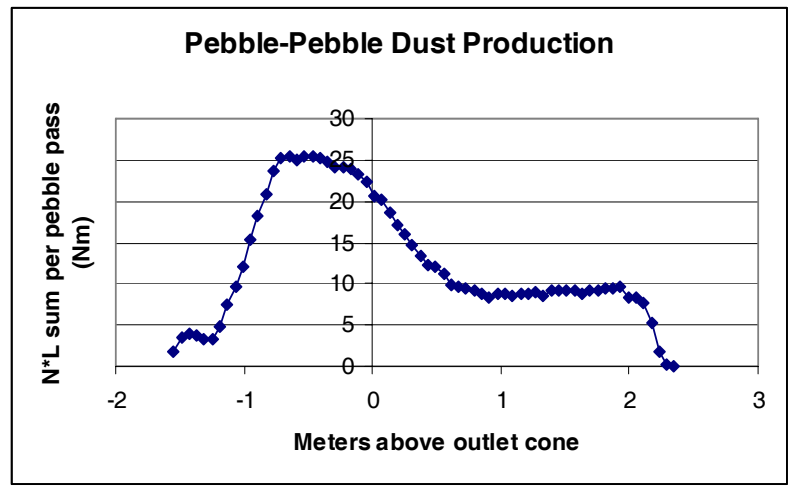

Figure 1 Pebble-Pebble Dust Production

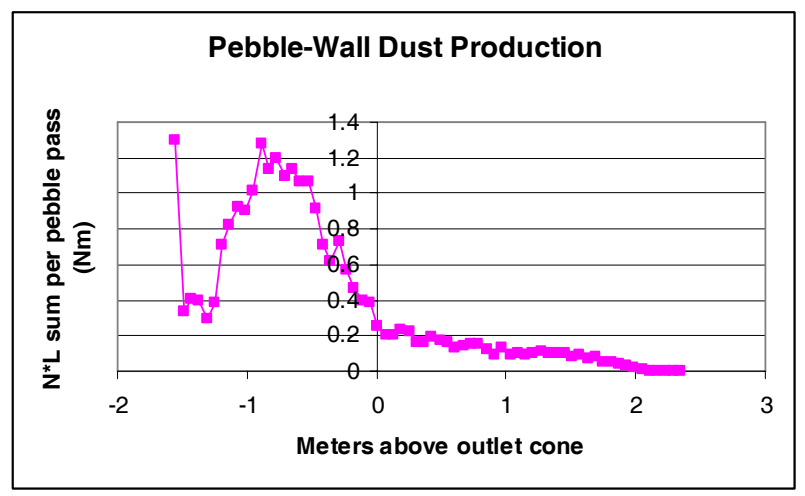

Figure 2 Pebble-Wall Dust Production

Calculating the graphite produced requires a relation between the sum of the normal length product and the physical quantity of dust produced. Since this relation is only approximate, any results will also only be approximate. Ideally the graphite wear data would be obtained for all the pressures and temperatures that occur in the pebble bed reactor. Sheng[7] provides $1.02 \times 10^{-6} \mathrm{~g} / \mathrm{m}$ as a line wear coefficient for graphite wearing on graphite with a $31 \mathrm{~N}$ load. This experiment was done in air at room temperature, but the paper mentions that wear rates could be 1000 times higher under other conditions. That room temperature experiment provides a wear coefficient of $3.290 \mathrm{e}-8$ $\mathrm{g} /(\mathrm{Nm})$. Two other papers[8,9] provide wear coefficients for graphite in different temperatures and normal forces including in helium at $400^{\circ} \mathrm{C}$, but inconsistent units make use of their data problematic. The papers do show a factor of 10 increase between room temperature and in helium at $400^{\circ} \mathrm{C}$. Under certain regimes 'dusting' wear in graphite occurs and wear rates on the order of $2 \mathrm{e}-5 \mathrm{~g} /(\mathrm{Nm})$ can occur[10]. 


\begin{tabular}{|l|r|r|}
\hline & $\begin{array}{l}\text { Pebble- } \\
\text { Pebble Dust }\end{array}$ & $\begin{array}{l}\text { Pebble-Wall } \\
\text { Dust }\end{array}$ \\
\hline $\begin{array}{l}\text { per pass N*L } \\
\text { sum }\end{array}$ & 0.876604 & 0.026103 \\
\hline $\begin{array}{l}\text { true per pass } \\
\text { N*L sum }\end{array}$ & 802.2159 & 23.88756 \\
\hline $\begin{array}{l}\text { mass (g) per } \\
\text { pass }\end{array}$ & $2.64 \mathrm{E}-05$ & $7.86 \mathrm{E}-07$ \\
\hline per year in kg & 0.003854 & 0.000115 \\
\hline
\end{tabular}

Table 2 AVR Dust Production Simulation Results

Using the $3.290 \mathrm{e}-8 \mathrm{~g} /(\mathrm{Nm})$ wear rate the simulation calculates that 4.0 grams of graphite dust per year should be produced in the AVR core. This is nearly 3 orders of magnitude less than the amount of graphite dust that was actually measured as produced in AVR. There are three reasons that the simulation should be producing lower values for dust production than actually occurred. First, using a dust production constant measured in air at room temperature should underestimate the actual AVR dust production in helium which had temperatures of over $900^{\circ} \mathrm{C}$ by at least a factor of 10 . If the in reactor conditions create a 'dusting' regime, then a factor of 1000 increase in wear could be possible. Secondly, the simulation models the walls as a cylinder, but in AVR and other designs the walls have dimples to prevent a crystalline pebble structure from developing. Lastly, the present simulation only simulated fuel handling inside the reactor core, and did not simulate fuel handling after the pebble leaves the reactor core. The AVR fuel handing system was believed to be responsible for most of the fractured spheres. Fuel handling involves contact of the pebbles with moving machinery and pneumatic transport of the pebbles so the fuel handling system likely produced significant quantities of additional dust.

Quality data on graphite wear for all the regimes of temperature, atmosphere, pressure, velocity and other factors in a pebble bed reactor are needed for believable dust production from discrete element methods. Measuring separate dust production rates in a working reactor from the fuel handling system and the reactor core would be valuable both for reducing the quantity of dust produced and for validation of codes that calculate the dust production.

\section{DISCUSSION/SUMMARY}

The discrete element method has the potential to be used for calculation of dust production quantities in production sized reactors. The discrepancies between the experimental result and the simulated result show that further refinement of the model is required. The physical constants that the model uses for dust production will need to be examined. Since the wear varies depending on the temperature, full refinement will require coupling of the pebble motion simulation with in core temperature data. The assumption of dust production being proportional to $\mathrm{N} * \mathrm{~L}$ will need to be examined. If full wear data for all the forces and temperatures can be determined, then the simulation could directly calculate dust produced. More of the reactor including the fuel handling will need to be modeled. These refinements are expected to reduce the difference between the experimentally calculated values and the simulated dust production values.

\section{ACKNOWLEDGEMENTS}

This work was supported in part by the Next Generation Nuclear Plant (NGNP) project at the Idaho National Laboratory, under the auspices of the Department of Energy, Office of Nuclear Energy, Science, and Technology, under DOE Idaho Operations Office Contract DE-AC07-05ID14517. Javier Ortensi and Robert L Bratton assisted with location of graphite data.

This manuscript has been authored by Battelle Energy Alliance, LLC under Contract No. DE-AC07-05ID14517 with the U.S. Department of Energy. The United States Government retains and the publisher, by accepting the article for publication, acknowledges that the United States Government retains a nonexclusive, paid-up, irrevocable, world-wide license to publish or reproduce the published form of this manuscript, or allow others to do so, for United States Government purposes.

\section{REFERENCES}

[1] Bhushan, Bharat, 2000, Modern Tribology Handbook, CRC Press, Boca Raton, Florida, USA, Chap. 7.5

[2] Marion, Jerry B. and Thornton, Stephen T., 1995, Classical Dynamics of Particles and Systems, Harcourt, Austin, Texas, Chap. 2, 11

[3] Wait, R. 2001, "Discrete Element Models of Particle Flows", Mathematical Modeling and Analysis, 6(1), pp. 156164

[4] Vu-Quoc, Loc, Zhang, Xiang and Walton, O.R., 2000, “A 3-D Discrete-element Method for Dry Granular Flows of Ellipsoidal Particles", Computer Methods in Applied Mechanics and Engineering, 187, pp. 483-528

[5] Kohring, G. A. 1995, "Studies of Diffusional Mixing in Rotating Drums via Computer Simulations" Journal de Physique I, 5(12) pp. 1551-1561

[6] Bäumer, R. et al, 1990, AVR - Experimental HighTemperature Reactor, VDI-Verlag GmbH, Düsseldorf, Germany, pp. 89,139,190,198, 267

[7] Sheng, X. Yu, S., Luo, X. and He, S. 2003, "Wear Behavior of Graphite Studies in an Air-conditioned Environment", Nuclear Engineering and Design, 223, pp. 109-115

[8] Lou, Xiaowei, Zhang, Lihong, and Suyuan, Yu, 2004, “The Wear Properties of Nuclear Grade Graphite IG-11 under Different Loads", International Journal of Nuclear Energy Science and Technology, 1(1), pp. 33-43

[9] Lou, Xiaowei, Suyuan, Yu, Xuanyu, Sheng, and Shuyan, He, 2005, "Temperature Effects on IG-11 Graphite Wear Performance", Nuclear Engineering and Design, 235, pp. 22612274

[10] Lancaster, J.K. and Pritchard, J.R. 1981, "The Influence of Environment and Pressure on the Transition to Dusting Wear of Graphite", Journal of Physics D: Applied Physics, 14(4), pp. 747-762 